\title{
Use of a Powered Stapling System for Minimally Invasive Lung Volume Reduction Surgery: Results of a Prospective Double-Blind Single-Center Randomized Trial
}

\author{
Ali Akil ${ }^{1} \quad$ Michael Semik $^{1}$ Stefan Freermann ${ }^{1} \quad$ Jan Reichelt $^{1}$ Bassam Redwan ${ }^{1}$ Dennis Görlich ${ }^{2}$ \\ Stefan Fischer ${ }^{1}$
}

${ }^{1}$ Department of Thoracic Surgery and Lung Support, Klinikum Ibbenbüren, Ibbenbueren, Germany

2 Institute of Biostatistics and Clinical Research, University of Muenster, Muenster, Germany

Address for correspondence Ali Akil, Department of Thoracic Surgery and Lung Support, Klinikum Ibbenbüren, Grosse Strasse 41, Ibbenbueren 49477, Germany (e-mail: dr.ali.akil.11@gmail.com).

Thorac Cardiovasc Surg 2019;67:216-221.

\author{
Abstract \\ Keywords \\ - linear stapling device \\ - lung volume \\ reduction surgery \\ - lung emphysema \\ - video assisted \\ thoracoscopic \\ surgery
}

Background Video-assisted thoracoscopic surgery (VATS)-lung volume reduction surgery (LVRS) represents an important treatment option for patients with advanced lung emphysema. For VATS lung resection, endoscopic staplers are routinely used. Recently, a new generation of electronically powered stapling systems was developed. In this study, the iDrive powered stapling system (Covidien, Germany) was first tested during VATS-LVRS and compared with a non-electronic conventional device.

Methods Forty patients with advanced emphysema were enrolled in a prospective randomized trial. All patients underwent bilateral VATS-LVRS. Patients were randomized for iDrive use on the right lung $(n=20)$ or left lung resection $(n=20)$. A conventional endoscopic stapler (EndoGIA, Covidien) was used for contralateral resection in same patients. Therefore, 40 resections were performed with the iDrive and 40 with the EndoGIA. The duration of surgery, air leakage after extubation, and on postoperative day 1 (POD1), as well as length of chest tube therapy, were documented. Results The application of the new system was uneventful. Mean duration of surgery was $52 \pm 2.5$ minute in the iDrive group compared with $54 \pm 3.8$ minute in the EndoGIA-group $(p=0.5)$. After extubation, the mean air leakage in the iDrive-group did not differ significantly from that in the EndoGiA-group $(p=0.6)$. This was also observed on POD1 ( $p=0.7$ ). Moreover, length of drainage therapy also did not show significant differences between both groups $(p=0.6)$.

Conclusion The iDrive powered stapling system offers one-handed, push-button operation, which eliminates the manual firing force and possibly enables more precise resection. In the current study, the novel system led to comparable results with the conventional mechanical stapler without any disadvantages in patients undergoing bilateral VATS-LVRS. (c) 2019 Georg Thieme Verlag KG Stuttgart · New York
DOI https://doi.org/ 10.1055/s-0037-1606313. ISSN 0171-6425. 


\section{Introduction}

Pulmonary resection performed by video-assisted thoracoscopic surgery (VATS) applying endoscopic staplers is increasingly becoming a standard procedure in advanced thoracic surgery. ${ }^{1,2}$ The use of endoscopic staplers for VATS was first reported in the late 1950s and early 1960s and has since then been constantly developed and modified. ${ }^{3-6}$ During the past decades, such staplers have led to safer and easier thoracoscopic pulmonary resection. Therefore, the role of thoracoscopic approaches to pulmonary resection especially for patients undergoing lung volume reduction surgery (LVRS) has relevantly increased. ${ }^{7-10}$ Not only with the development of more specific diagnostics, but also by the introduction of endoscopic lung volume reduction strategies, the outcome after LVRS has been improved, and the popularity is increasing. ${ }^{11-13}$ Obviously, one major focus in the development of endoscopic stapling devices is to achieve more precision and safety in VATS-LVRS thereby avoiding postoperative complications, which consequently may contribute to further decrease in morbidity and mortality.

The iDrive system (Covidien, Germany) is an electronically powered stapling system made for VATS lung resection. The aim of this study was to evaluate the effectivity and safety of the IDrive powered stapling system in patients undergoing VATS-LVRS and to compare the outcome to a conventional mechanical stapling device (EndoGIA, Covidien, Germany).

\section{Materials and Methods}

\section{Population of Patients and Assessments}

Between January 2014 and December 2015, 40 patients with severe emphysema underwent a bilateral VATS-LVRS. A prospective randomized trial to compare the surgical results between two different endoscopic staplers was performed after receiving approval from the institutional ethics committee. All patients gave their consent to the study pre-operatively. The following factors served as exclusion criteria: age $<18$ and $>80$, pregnancy, and re-operation.
Before surgery, all patients included in the trial were subjected to the following evaluation procedures and measurements: electrocardiogram (ECG), transthoracic echocardiography, lung function testing (forced expiratory volume 1 [FEV1], vital capacity [VC], total lung capacity [TLC], and residual volume [RV]), 6-minute walk test, blood gas analysis, three-dimensional computed tomographic [3D-CT] lung volumetry, and ventilation/perfusion lung scintigraphy scanning.

Patients randomly assigned to VATS-LVRS underwent bilateral lung shaving using the iDrive (iDrive group) on the right side $(n=20)$ or the left side $(n=20)$. For the contralateral resection a conventional endoscopic stapling device by the same manufacturer (EndoGIA, Covidien, Germany) was used (EndoGIA group). In all 40 patients, the right side was resected first. Study groups were depicted in - Fig. 1 (see also consort flow diagram, -Supplementary Fig. S1 and - Supplementary Table S1, available online only).

The duration of surgery, air leakage after extubation and on postoperative day 1 (POD1), as well as the length of drainage therapy were prospectively recorded. The air leakage was quantified with a digital drainage system (Thopaz, Medela, Germany).

\section{The iDrive Stapling Device}

The iDrive powered stapling system is a fully powered reusable endostapler. It offers a one-handed, push-button operation that eliminates the usually applied manual firing force. It consists of a mounted control unit and a loading unit with a ridged shaft. The control unit allows controlling the accurate placement of the cartridge by orientating the tip of the shaft, as well as the closure and the firing step. The loading unit is compatible with the EndoGIA and Tri-Staple cartridges (Covidien, Germany). The stapler line length was $60 \mathrm{~mm}$. For peripheral parts of the lung tissue $60-\mathrm{mm}$ purple staple line was applied with staple size between 1.5 and $2.25 \mathrm{~mm}$. For central parts of the lung tissue, black staple lines were used with a staple size between 2.25 and $3.0 \mathrm{~mm}$. Furthermore, ergonomic fingertip control offers unlimited points of articulation between the $45^{\circ}$ left and right limit.

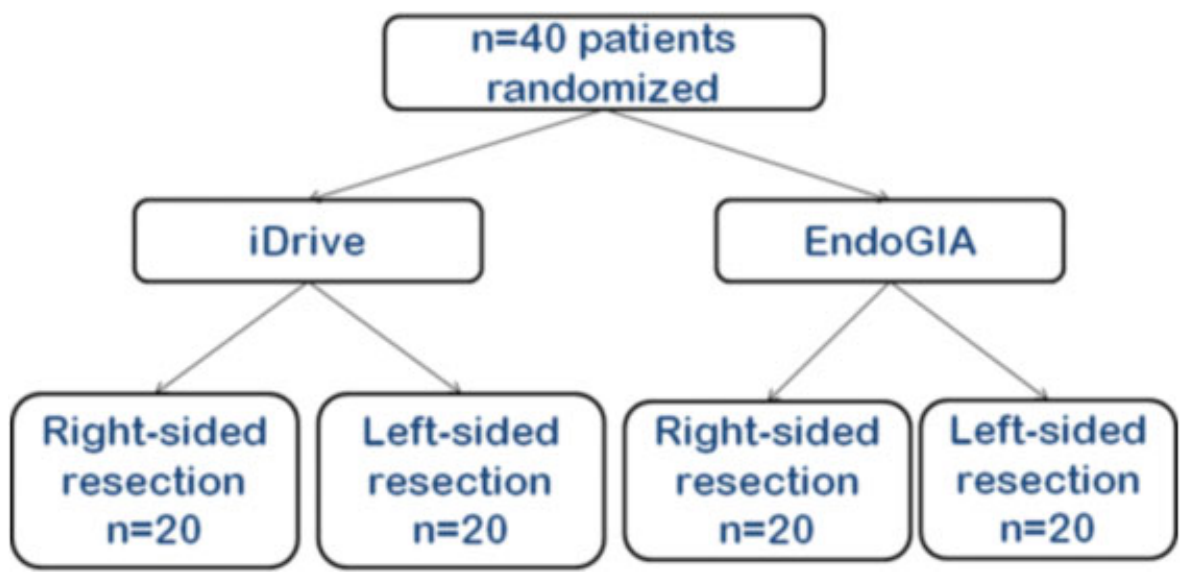

Fig. 1 Figure shows the study group. 
Table 1 Area of resection involved mostly the upper lobe. Primary and secondary end points of the study are also listed

\begin{tabular}{|l|l|l|l|l|}
\hline & & iDrive group & EndoGIA-group \\
\hline \multirow{4}{*}{ Area of resection } & Upper lobe & 25 & & 23 \\
\cline { 2 - 5 } & Middle lobe/lingula & 3 & & 2 \\
\cline { 2 - 5 } & Lower lobe & 12 & & 15 \\
\hline Primary end points & Air leak after extubation & $230 \pm 81(0-2,300)$ & $p=0.6$ & $321 \pm 116(0-3,400)$ \\
\hline Secondary end points & Duration of surgery & $52 \pm 2.5(29-93)$ & $p=0.5$ & $54 \pm 3.8(21-105)$ \\
\cline { 2 - 5 } & Air leak on POD1 & $308 \pm 94(0-2,200)$ & $p=0.7$ & $255 \pm 95(0-2,300)$ \\
\cline { 2 - 5 } & Length of drainage therapy & $7 \pm 1(4-16)$ & $p=0.6$ & $8 \pm 1(5-15)$ \\
\hline
\end{tabular}

Abbreviation: POD, postoperative day 1.

\section{Statistical Analysis}

For the analysis of the trial, the outcome variable air leakage after extubation was used to test the primary hypothesis of no difference, that is, equivalence of the two procedures (iDrive versus EndoGIA). The outcome duration of surgery air leakage on POD1 and length of drainage therapy were considered as secondary outcomes ( - Table $\mathbf{1}$ ). Data was analyzed according to the intention-to-treat principle. Categorical variables were described as absolute and relative frequencies. Continuous variables were described using means, standard deviations, and ranges. Boxplots show the distribution of the continuous variables within the groups, and additionally scatter plots display the association of the paired data. Comparisons between continuous operative and postoperative parameters of both groups (iDrive group versus EndoGIA group) were performed using paired $t$-tests, assuming normality of the differences. Test results were reported as mean difference between both procedures and the corresponding 95\% confidence interval (CI). The limits of the 95\% CI were interpreted in the sense of an equivalence test. Equivalence margins were not pre-specified. Superiority $p$-values of the paired $t$-tests were reported for informational purpose, but were not further interpreted to make any conclusions.

\section{Results}

A total of 40 patients ( 13 women) with a mean age of $65 \pm 4$ years undergoing bilateral VATS-LVRS were included and analyzed. The area of resection and primary end points of the study are depicted in -Table 1. No major complications such as hemorrhage, wound infection, persistent air leakage, and re-operation were noticed. All patients were preoperatively presented with a severe obstructive lung function (mean $\mathrm{FEV} 1=0.96$, mean $\mathrm{VC}=2.23$, mean $\mathrm{TLC}=7.31$, and mean $\mathrm{RV}=7.2$ ).

Surgical lung volume reduction was performed bilaterally by VATS in all patients. ${ }^{14,15}$ The mean duration of surgery was $52 \pm 2.5$ minutes (range: $29-93$ minutes) in the iDrive group and $54 \pm 3.8$ minutes (range: 21-105 minutes, $p=0.5,95 \% \mathrm{CI}:-11.98$ to 10.28 ) in the EndoGIA group (-Fig. 2). The mean overall amount of magazines used for both stapler groups was identical ( $n=5$ magazines). For the left- and right-sided resection with the iDrive stapler, a mean of six magazines was used. In comparison, a mean of five magazines was used for the left-sided resection and six magazines for the right-sided resection with the mechanical stapler. Two chest tubes were placed on each side and were connected to a digital drainage system with suction of $-10 \mathrm{~cm} \mathrm{H}_{2} \mathrm{O}$. All patients were extubated in the operating room. The air leakage after extubation ( - Fig. 3) and on POD1 (-Fig. 4) was recorded by the digital drainage system. In the iDrive group, the mean air leakage after extubation was $230 \pm 81 \mathrm{~mL} / \mathrm{min}$ (range: $0-2,300 \mathrm{~mL} / \mathrm{min}$ ) compared with $321 \pm 116 \mathrm{~mL} / \mathrm{min}$ (range: $0-3,400 \mathrm{~mL} / \mathrm{min}$ ) for the EndoGIA group ( $p=0.6,95 \% \mathrm{CI}$ : -206.9 to 291.4 ). On POD1, a mean air leakage of $308 \pm 94 \mathrm{~mL} / \mathrm{min}$ (range: $0-2,200 \mathrm{~mL} / \mathrm{min}$ ) was observed in the iDrive group and $255 \pm 95 \mathrm{~mL} / \mathrm{min}$ (range: $0-2,300 \mathrm{~mL} / \mathrm{min})$ in the EndoGIA group ( $p=0.7,95 \%-\mathrm{CI}$ : -273.2 to 182.2 ). Therefore, no significant differences were observed. When comparing the right and left side regarding the air leak on the day of surgery regardless of the staple device utilized, we noticed a trend toward higher air leakage on the right side, which was always the first side for resection in all patients. The mean air leakage on the right side was $358 \pm 119 \mathrm{~mL} / \mathrm{min}$ (range: $0-3,400 \mathrm{~mL} / \mathrm{min}$ ) compared with $162 \pm 50 \mathrm{~mL} / \mathrm{min}$ (range: $0-1,100$ ) on the left side (-Fig. 5). Although a clear trend was, therefore, seen, we also could not

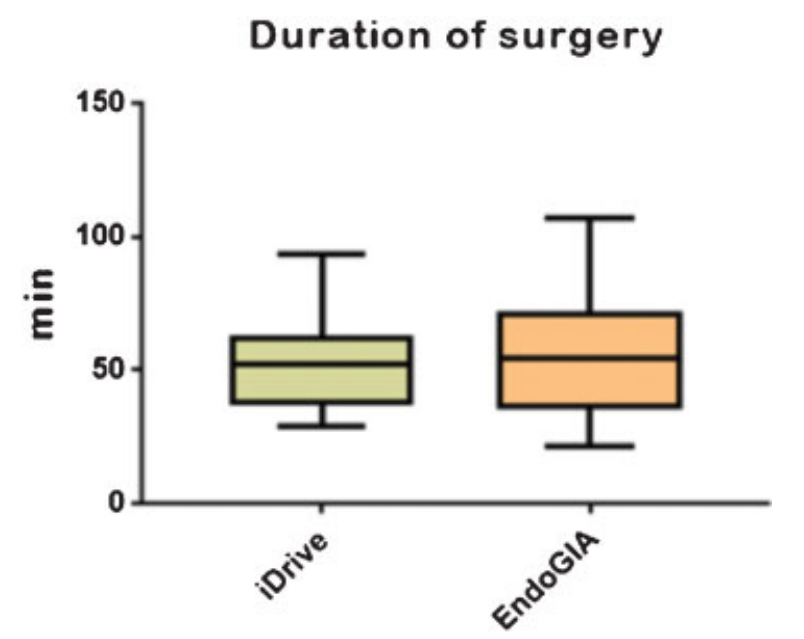

Fig. 2 It is shown that the applied stapler did not have any influence on the mean duration of surgery. 

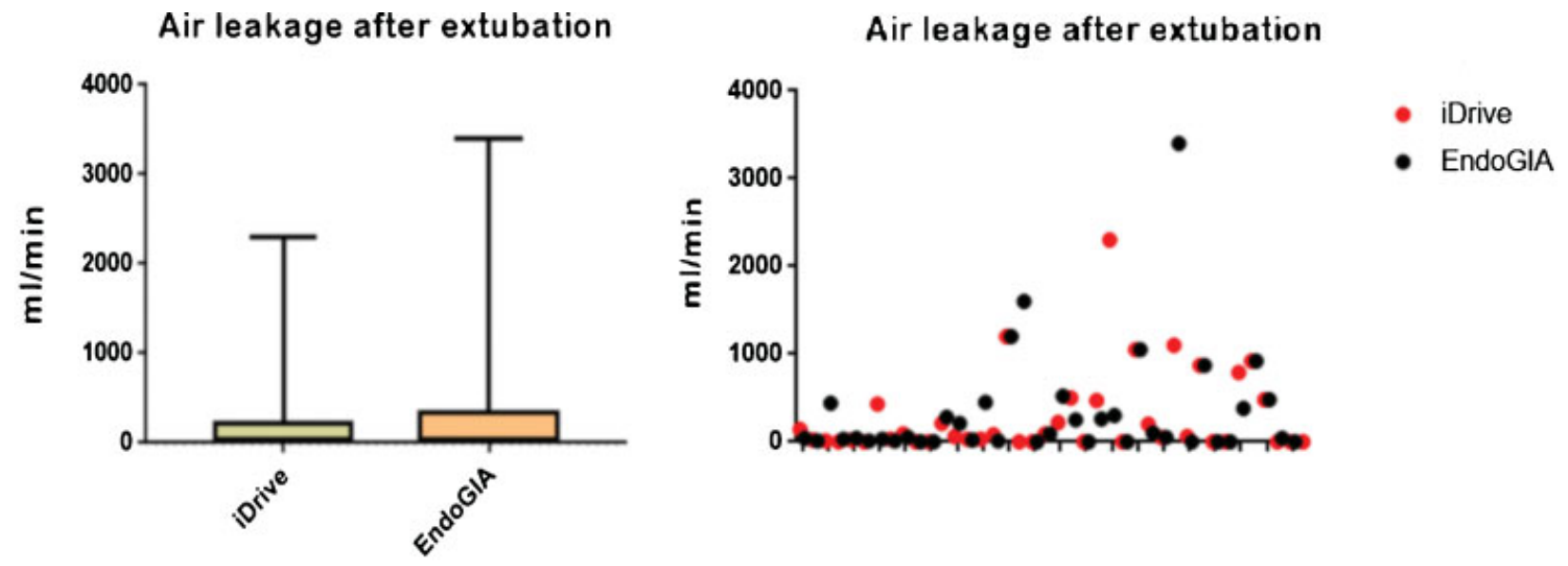

Fig. 3 Air leakage after extubation did not show any statistical difference between both staples. Scatter plots show the normal association of the paired data.

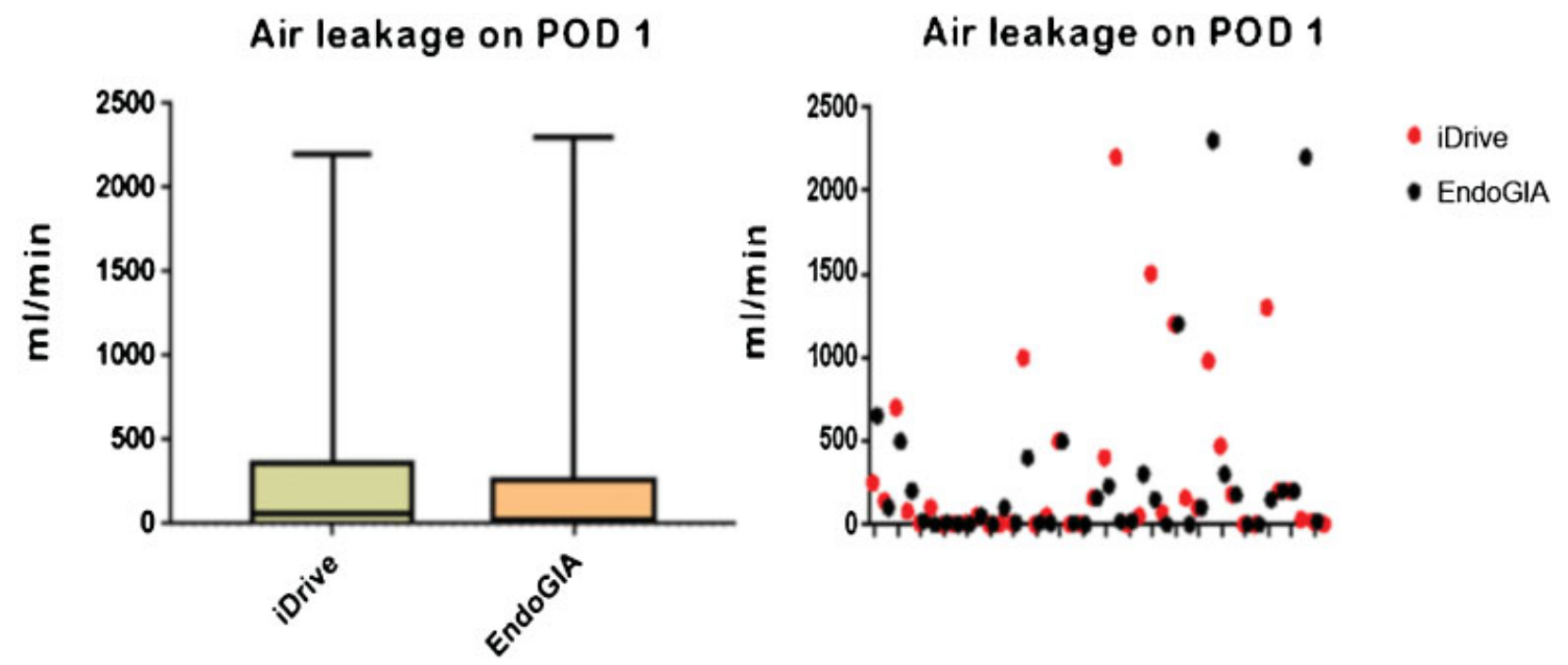

Fig. 4 The air leakage on POD1 was almost comparable for both staplers. Scatter plots show the normal association of the paired data. POD, postoperative day 1.

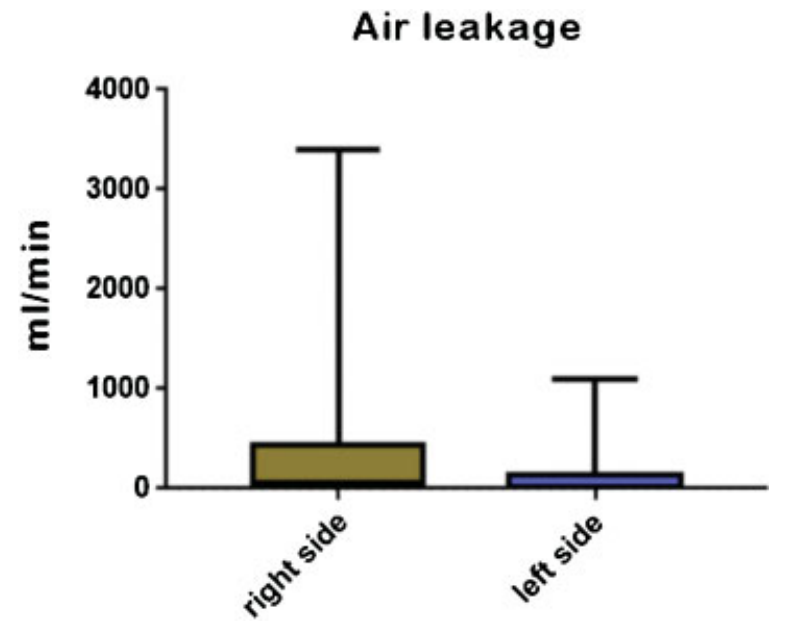

Fig. 5 An overall higher air leakage was observed on the right side when compared with the left side independently form the used staplers. show any statistical difference between both sides. Regarding the length of drainage therapy, once again no significant differences between both sides were observed with a mean duration of $7 \pm 1$ days (range: 4-16 days) for the iDrive group and $8 \pm 1$ days (range: $5-15$ ) for the EndoGIA group $(p=0.6)$, as depicted in - Fig. 6 . Chest tubes were removed after no air leakage was detected by the digital system for 24 hours.

\section{Discussion}

Endoscopic staplers allow for simultaneous resection and tissue closure in excellent quality especially when applied for minimally invasive lung resection. Furthermore, the VATS approach is now widely used for the surgical treatment of severe pulmonary emphysema. To perform such procedures, a variety of endoscopic stapling devices with different characteristics were used. Significant advantages expected are the 


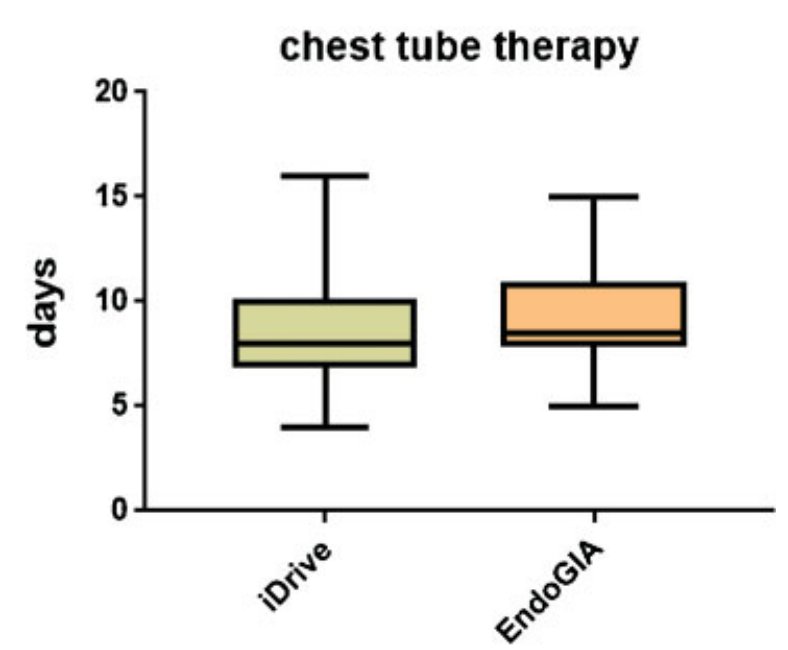

Fig. 6 The chest tube duration with comparable results between both staplers is shown.

easy handling, secure closure of the lung tissue, as well as avoiding prolonged air leakage after surgery. Due to the necessary sheer force of the stapling device during application, undesirable lung injury might occur in some cases. This could lead to prolonged air leakage, which might be associated with prolonged chest tube drainage. It was reported, that buttressed staple lines with biologica ${ }^{16}$ or synthetic materials allow reducing air leakage leading to chest tube removal. ${ }^{17,18}$ Despite the cost-intensive material, those studies have shown, in general, the effectiveness of the buttressed staple lines.

Gossot and Nana reported a computer-controlled stapling system, which allows selecting an appropriate staple height and controls the selection of the staple based on tissue diameter. ${ }^{19}$ Although this stapling system seems to be safe and precise in comparison to conventional mechanical staplers, there were several disadvantages mentioned. Some intrathoracic space limitations were observed during VATS resection due to the length of the articulated tip of the flexible shaft. Additionally, it is favorable to have a rigid shaft to apply the required force to load the parenchyma within the staple jaw or to turn it around the bronchial structures. ${ }^{19}$

To avoid the confounding factor of different stapler units between both groups, the same kind of staple magazine was used for both staple systems in this study.

The iDrive system was first described for lung resection by a Japanese group. ${ }^{20}$ In this study, the efficacy and safety during different procedures for lung resection was tested in a prospective fashion. There were no stapling failures noticed and no complications mentioned related to the use of the iDrive stapler. A limitation of that study was the lack of a control group.

In this study a randomized prospective concept on 40 patients undergoing bilateral VATS-LVRS was chosen. The expected advantage, which has also been a force for developing electronical stapling devices, was to reduce mechanical stress on lung tissue, which could influence lung injury, prolonged air leakage, morbidity, and prolonged hospital stay. However, this has never been tested in a prospective randomized fashion. An intriguing aspect of this study design here is that, given the bilateral surgical approach, both stapling devices were applied to all patients: the EndoGIA on one side and the iDrive on the other side were dependent on the randomization. Again, both devices were reloaded with the Tri-Staple cartridges. We could not show any statistical difference between both staplers regarding the post-operative air leak or duration of chest tube drainage. Also, we did not have any technical malfunction during the application of both staplers. Interestingly, a higher air leakage was documented for the right side after resection in comparison to the left side. Most likely, the single lung ventilation of the first resected lung, which was in all study patients the right lung, to enable left lung resection may have contributed to these findings.

For this study we have particularly chosen patients undergoing bilateral LVRS for end-stage lung emphysema because it is well known that these patients tend to show postresection air leak due to the over-inflation of the lung and the reduced tissue diameter. Severe air leakage in this specific patient cohort has been described to be a major and routinely seen postoperative complication. ${ }^{21}$ Since postlung resection air leak is the major end-point in this study, we chose to include only patients who underwent surgery specifically for lung emphysema.

In this study, the use of an electronic stapling device has not been proven to be superior to commonly used mechanical handhelds with regards to the amount of postoperative air leakage, the consecutive length of chest tube drainage, and the time of surgery.

\section{Disclaimer}

The German Society for Thoracic and Cardiovascular Surgery (DGTHG) and The Thoracic and Cardiovascular Surgeon neither endorse nor discourage the use of the new technology described in this publication.

\section{Funding}

No funding sources.

Conflict of Interest

None declared.

\section{Acknowledgment}

We would like to thank Covidien Company in Germany for providing staplers for the study.

\section{References}

1 Molnar TF. (Video Assisted) thoracoscopic surgery: Getting started. J Minim Access Surg 2007;3(04):173-177

2 Roviaro G, Varoli F, Vergani C, Maciocco M, Nucca O, Pagano C. Video-assisted thoracoscopic major pulmonary resections: technical aspects, personal series of 259 patients, and review of the literature. Surg Endosc 2004;18(11):1551-1558

3 Amosov NM, Berezovsky KK. Pulmonary resection with mechanical suture. J Thorac Cardiovasc Surg 1961;41:325-335

4 Ravitch MM, Steichen FM, Fishbein RH, Knowles PW, Weil P. Clinical experiences with the Soviet mechanical bronchus stapler (UKB-25). J Thorac Cardiovasc Surg 1964;47:446-454

5 Acuff TE, Mack MJ, Landreneau RJ, Hazelrigg SR. Role of mechanical stapling devices in thoracoscopic pulmonary resection. Ann Thorac Surg 1993;56(03):749-751 
6 Hood RM, Kirksey TD, Calhoon JH, Arnold HS, Tate RS. The use of automatic stapling devices in pulmonary resection. Ann Thorac Surg 1973;16(01):85-98

7 Fishman A, Martinez F, Naunheim K, et al; National Emphysema Treatment Trial Research Group. A randomized trial comparing lung-volume-reduction surgery with medical therapy for severe emphysema. N Engl J Med 2003;348(21):2059-2073

8 Naunheim KS, Wood DE, Mohsenifar Z, et al; National Emphysema Treatment Trial Research Group. Long-term follow-up of patients receiving lung-volume-reduction surgery versus medical therapy for severe emphysema by the National Emphysema Treatment Trial Research Group. Ann Thorac Surg 2006;82(02): 431-443

9 Lowdermilk GA, Keenan RJ, Landreneau RJ, et al. Comparison of clinical results for unilateral and bilateral thoracoscopic lung volume reduction. Ann Thorac Surg 2000;69(06):1670-1674

10 Boley TM, Reid AJ, Manning BT, Markwell SJ, Vassileva CM, Hazelrigg SR. Sternotomy or bilateral thoracoscopy: pain and postoperative complications after lung-volume reduction surgery. Eur J Cardiothorac Surg 2012;41(01):14-18

11 Bingisser R, Zollinger A, Hauser M, Bloch KE, Russi EW, Weder W. Bilateral volume reduction surgery for diffuse pulmonary emphysema by video-assisted thoracoscopy. J Thorac Cardiovasc Surg 1996;112(04):875-882

12 Ginsburg ME, Thomashow BM, Yip CK, et al. Lung volume reduction surgery using the NETT selection criteria. Ann Thorac Surg 2011;91(05):1556-1560, discussion 1561
13 DeCamp MM Jr, McKenna RJ Jr, Deschamps CC, Krasna MJ. Lung volume reduction surgery: technique, operative mortality, and morbidity. Proc Am Thorac Soc 2008;5(04):442-446

14 Stammberger U, Thurnheer R, Bloch KE, et al. Thoracoscopic bilateral lung volume reduction for diffuse pulmonary emphysema. Eur J Cardiothorac Surg 1997;11(06):1005-1010

15 Klepetko W. Surgical aspects and techniques of lung volume reduction surgery for severe emphysema. Eur Respir J 1999;13 (04):919-925

16 Hazelrigg SR, Boley TM, Naunheim KS, et al. Effect of bovine pericardial strips on air leak after stapled pulmonary resection. Ann Thorac Surg 1997;63(06):1573-1575

17 Roberson LD, Netherland DE, Dhillon R, Heath BJ. Air leaks after surgical stapling in lung resection: a comparison between stapling alone and stapling with staple-line reinforcement materials in a canine model. J Thorac Cardiovasc Surg 1998;116(02):353-354

18 Juettner FM, Kohek P, Pinter H, Klepp G, Friehs G. Reinforced staple line in severely emphysematous lungs. J Thorac Cardiovasc Surg 1989;97(03):362-363

19 Gossot D, Nana A. Computer-controlled stapling system for lung surgery. Ann Thorac Surg 2005;80(05):1898-1901

20 Satoh Y, Hayashi S, Yamazaki H, Mikubo M, Naito M, Shiomi K. [Ultra powered stapling system for general lung surgery]. Kyobu Geka 2014;67(03):225-228

21 Cerfolio RJ, Tummala RP, Holman WL, et al. A prospective algorithm for the management of air leaks after pulmonary resection. Ann Thorac Surg 1998;66(05):1726-1731 